\title{
Modeling of scenarios for the implementation of eco-technological innovation to ensure transition to a low carbon economy based on game theory
}

\author{
Elena Razumovskaya ${ }^{1, *}$, Denis Razumovsky ${ }^{2}$, Zhenglian Tang $^{3}$ \\ ${ }^{1}$ Department of Finance, Monetary Circulation and Credit, Ural Federal University, Yekaterinburg, \\ Russia \\ ${ }^{2}$ Ural Institute of Management - branch Russian Academy of National Economy and Public \\ Administration under the President of the Russian Federation, Yekaterinburg, Russia \\ ${ }^{3}$ Ural State University of Economics, Yekaterinburg, Russia
}

\begin{abstract}
Achieving sustainable economic development is achieved by high-tech innovations in the field of IT. The orientation of technical innovations towards the ecological principles of organizing modern industries in all sectors of the economy is designed to ensure the transition to a low-carbon model of global development. At the first stage of the transition, it is planned to create and apply systems for reducing greenhouse gas emissions through quotas and tax incentives. The advantages and disadvantages of a low-carbon model are extremely difficult to assess in practice, since such an assessment is associated with predictive calculations of external effects. In order to overcome these difficulties, the authors made an attempt to apply the methods of mathematical modeling from the standpoint of game theory. In particular, a model analysis of the strategy of highly toxic, polluting and high-energyintensive industries in the public sector and the investment strategy of ecotechnological innovations of private companies was carried out. Based on the results of game modeling, the authors proposed a project for a new energy system "UHV technology", which involves investment financing of technical innovations of a low-carbon model for the development of the territories of the People's Republic of China.
\end{abstract}

\section{Introduction}

Modern research on the environmental threats facing humanity is becoming increasingly relevant. Following the popularity of the environmental activist and the

\footnotetext{
*Corresponding author: rasumovskaya.pochta@gmail.com
} 
symbol of youth struggle for an ecological future, G. Thunberg, the world saw the incredible result of the Green Party led by A. Berbock in the elections in Germany.

The issues of responsibility of today's generation to the future causes the need to revise the activities of industries and companies with a high level of pollution, causing deforestation and high energy consumption. The problems of the transition to energy neutrality and low-carbon production are attracting more and more public attention around the world, as they cause a warming of the climate throughout the planet [5]. People's awareness of the importance of environmental protection measures, the use of low-carbon and energy-saving technologies, and the reduction of air polluting emissions contributed to the Earth Day on April 22, 2021, during which the most influential personalities of the world made speeches: US President J. Biden, UN Secretary General A.M. ... Guterres, President of the Russian Federation V.V. Putin, who called on countries around the world to end fossil fuel subsidies and increase investment in renewable energy and environmental infrastructure. Chinese President Xi Jinping announced that China is striving to achieve carbon neutrality by 2060 , which makes programs to promote low-carbon production a priority in addressing China's environmental challenges. Achieving a global consensus through the efforts of developed countries is intended to create conditions for the economic feasibility of creating high-tech innovations in the field of sustainable global development.

Many countries have already begun to implement new environmental standards for their emission systems and introduce carbon quotas. Quantitative regulatory instruments for environmental policy can be called "carbon trading" because in practice they are a typical application of a government pollution permit, which is consistent with the theory of R. Coase. Compensation payments, in fact, are designed to compensate for the negative effects of external externalities, but, according to the authors, do not eliminate the causes of environmental problems. Quantitative regulation can be viewed as a tax on carbon emissions, that is, a public policy instrument similar to A. Pigou's tax. However, "cap-andtrade" at the current stage is the most effective and acceptable market mechanism for reducing emissions for most countries in the world.

Application of cap-and-trade regulatory principles is reviewed by Samaras C., Apt J., Azevedo I.L. as an insufficient measure for the transition to a balanced low-carbon model of global development [8]. To achieve this goal, a number of scientists consider it necessary to invest in technologies to reduce carbon emissions [3].

In the corporate context of a global low-carbon development model, almost all traditional and high-carbon energy sources can be replaced by new energy sources, and almost all companies with high levels of pollution and energy consumption («two highs») can go out of business and transform completely. In order to survive and transform, the «two highs» companies will have to increase investment in technologies to reduce carbon emissions while gaining (or maintaining) a competitive market advantage in manufacturing. Low-carbon transformation should be seen as the foundation of competitiveness in the future society, which will increase market efficiency through innovation in environmental technologies, thereby solving the problem of climate change.

On the part of the state, as a participant in the implementation of the global low-carbon development model, a number of authors consider the only possible and sufficiently effective actions to be an increase in subsidies for environmental innovation, tax regulation and adherence to a policy of economic incentives, which together can compensate for market failures and contribute to the transformation of the industrial structure for a sustainable economic development [9].

A third party to the ongoing changes are investors who analyze investment risks due to the lack of accurate information about the prospects for the use of low-carbon technologies. 
Therefore, many investors use scientific methods of mathematical modeling to make decisions about the expansion or contraction of investments [10].

In this regard, the authors decided to use game theory in this study when analyzing the strategies of companies of the "two maximums", the state (government) and investors, which are implemented in the process of making decisions on the development and use of technological low-carbon innovations.

\section{Methods}

Scientific research in the field of traditional sustainable development concerns the issues of modeling the territories of the future [2] and overcoming poverty in a number of countries [7]. A special place in such studies is occupied by the transformation of urban landscapes [1]. The author's research attention is focused on the game model of interaction between companies of «two maximums», investors in technological innovation and the state. In the process of interaction, these parties have different value orientations. Companies, due to significant investments in high-tech innovation and slow results, will strive to choose an energy saving and emission reduction strategy. Investors will seek to reduce their participation in high-carbon and energy-intensive industries if the latter do not seek to transform, signaling their priorities. As a result, the market capitalization of these companies is likely to decline. At the same time, investors will have to face the investment risk assessment when assessing the potential of energy-saving, low-carbon and other environmentally neutral technologies. The state will maintain control over energy conservation and emission reductions by implementing economic regulation: subsidizing environmentally loyal ones as a reward and increasing the tax burden on companies in the "two maximums" category as a punishment for causing harm to the environment. An analysis of the value orientation of the three subjects of game modeling allows us to see that each of them has two main strategies for making decisions. Companies have "two maximums»: to invest or not to invest in innovative environmental technologies; for investors: to invest or not to invest in the creation and development of ecological production; from states: remuneration through subsidies and fines or financing of new technologies.

\subsection{Companies and state}

By pursuing a low-carbon strategy, the «two-caps» companies will transform by introducing eco-tech innovations to generate more investment. If eco-technological innovations are not implemented, then their normal income is E. When carrying out ecotechnological innovations, the cost of investments is $\mathrm{S}$, so the additional benefit received will be E0. When the government controls energy conservation and emission reductions, the cost of oversight is $\mathrm{C}$. The state gives appropriate remuneration to companies that carry out eco-technological innovations, the amount of which is G. Other profit of the company due to eco-technological innovations - H. The likelihood of implementation of ecotechnological innovations by "two maximums" companies $-\alpha ; \beta$ is the likelihood of government oversight, and $\theta$ is the likelihood of discovering a company's eco-tech innovations during government oversight. The initial conditions of the game model are set out in Table 1. 
Table 1. Model of the game «Supervision» between the company of «two maximums» by the state.

\begin{tabular}{|c|c|c|}
\hline $\begin{array}{c}\text { Strategy } \\
\text { Green } \\
\text { technology } \\
\text { innovation }\end{array}$ & $\begin{array}{c}\text { Supervision } \\
\text { E0 }-\mathrm{S}+\mathrm{G} \theta+\mathrm{H} \theta,-\end{array}$ & $\mathrm{E}+\mathrm{E}+\mathrm{E} 0-\mathrm{S} ; 0$ \\
\hline $\begin{array}{c}\text { Non-green } \\
\text { technological } \\
\text { innovation }\end{array}$ & $\mathrm{E} ;-\mathrm{C}$ & $\mathrm{E} ; 0$ \\
\hline
\end{tabular}

1.1. In the process of implementing ecotechnological innovations, companies expectations of benefits from the state are:

$$
\begin{gathered}
I_{\text {supervision }}=-C^{*}(1-\alpha)+\alpha^{*}(-\mathrm{G} \theta-\mathrm{C}) \\
\mathrm{I}_{\text {no supervision }}=0
\end{gathered}
$$

Equating the expected effect of government supervision and non-supervision, we obtain the equilibrium solution of J. Nash:

$$
\alpha=-\mathrm{C} / \mathrm{Gth}
$$

1.2. Under the control of the state, the expected income of the company is:

$$
\begin{gathered}
I_{\text {supervision }}=\beta^{*}(\mathrm{E}+\mathrm{E} 0-\mathrm{S}+\mathrm{G} \theta+\mathrm{H} \theta)+(1-\beta)^{*}(\mathrm{E}+\mathrm{E} 0-\mathrm{S}) \\
\mathrm{I}_{\text {no supervision }}=\beta^{*} \mathrm{E}+\mathrm{E}^{*}(1-\beta)
\end{gathered}
$$

If companies' expectations for eco-tech innovations are equal to the expected returns from the lack of eco-tech innovations, then the equilibrium solution of J. Nash can be obtained:

$$
\beta=(\mathrm{S}-\mathrm{E} 0) /(\mathrm{Gth}+\mathrm{Hth})
$$

\subsection{Companies and investors}

In order to avoid investment risks in the context of sustainable low-carbon development, investors will seek to verify the information of the companies of the «two highs» about their implementation of technological innovations. If the implementation of technological changes is not confirmed, investors will reduce investments or even stop them altogether. Suppose that when a company does not innovate in environmental technology, its normal return is E and the investor's normal return is R. When the company does eco-technological innovation, its input cost is $\mathrm{S}$, so the additional benefit received is $\mathrm{E} 0$. The cost invested by the investor in the verification process is $\mathrm{Y}$. When investors find that the «two maximums» company has not implemented eco-technological innovations, then, taking into account the investment risk, they will withdraw funds, then the companies loss is M, and the investor's loss is K The likelihood of innovation in the company's environmental technology $-\alpha, \beta-$ the probability of investor investment, $\delta$ - the likelihood that investors in the process of supervision will find that the company has not innovated in the field of environmental technology. The initial conditions of the game model are presented in table 2. 
Table 2. Model of the game «Supervision» between companies of «two maximums» by the state.

\begin{tabular}{|l|c|c|}
\hline \multicolumn{1}{|c|}{ Strategy } & Invest & Not invest \\
\hline $\begin{array}{c}\text { Green technology } \\
\text { innovation }\end{array}$ & $\mathrm{E}+\mathrm{E} 0-\mathrm{S} ; \mathrm{R}-\mathrm{Y}$ & $\mathrm{E}+\mathrm{E} 0-\mathrm{S} ;$ \\
$-\mathrm{Y}$
\end{tabular}

2.1. In the process of the companies eco-technological innovation, the expected return on the investor is:

$$
\begin{gathered}
\mathrm{I}_{\text {invest }}=(\mathrm{R}-\mathrm{Y}) * \alpha+(1-\alpha) *(\mathrm{R}-\mathrm{Y}-\mathrm{K} \delta) \\
\mathrm{I}_{\text {no invest }}=-\mathrm{Y}^{*} \alpha+(-\mathrm{Y}) *(1-\alpha)
\end{gathered}
$$

Equalizing the expected return of investors when investing and not investing, we obtained the equilibrium solution of J. Nash:

$$
\mathrm{A}=1-\mathrm{P} / \mathrm{K} \delta
$$

2.2. When an investor makes an investment, the company's expected return is:

$$
\begin{gathered}
I_{\text {no supervision }}=\beta^{*}(E 0-S)+(1-\beta) *\left(E^{\prime} E_{0}-S\right) \\
I_{\text {no supervision }}=\beta^{*}(E-M \delta)+E^{*}(1-\beta)
\end{gathered}
$$

If companies expectations regarding eco-tech innovations are equal to the expected returns from not introducing eco-tech innovations, we get the equilibrium solution of $\mathrm{J}$. Nash:

$$
\mathrm{B}=\mathrm{E} /(1+\mathrm{M} \delta)
$$

\section{Results}

1. The analysis of the simulation results of games between the companies of «two maximums» and the state is based on the equation:

$$
\alpha=-\mathrm{C} / \mathrm{G} \theta
$$

From the equilibrium solution for $\alpha$, it can be seen that the likelihood of companies in the «two-maximum» category of eco-technological innovations mainly depends on three variables, which are: the cost of government supervision (C); government remuneration $(\mathrm{G})$ for eco-technological innovation companies and government oversight process $(\theta)$. As the remuneration $\mathrm{G}$ increases, the likelihood $\alpha$ of the company's eco-tech innovation is higher. As the government recognizes the right to incentives for companies that undertake eco-technological innovations, the likelihood of these companies introducing ecotechnological innovations will certainly increase. To promote eco-technological innovations, the state can be recommended to reduce the costs of supervision, and at the expense of the released funds - to increase rewards for the introduction of eco-technological innovations. 
2. The analysis of the simulation results of the game between companies of «two maximums» and investors is described by the equation:

$$
\alpha=1-\mathrm{R} / \mathrm{K} \delta
$$

From the equilibrium solution for $\alpha$, it can be seen that the probability of companies' introducing «two maximums» of eco-technological innovations can mainly be realized based on the following logic: when the company does not innovate in the field of ecotechnologies, and then the investor receives a normal investment income $\mathrm{R}$, and since the company has not innovated in green technology, the investor loses $\mathrm{K}$. The likelihood that the investor discovers that the company has not innovated in green technology during the verification process $\theta$, negatively correlates with $R, K$, and $\delta$.

Investor losses can be reduced by increasing the likelihood of eco-technological innovations being introduced by "two highs" companies. At the same time, when investors find that the likelihood of a company abandoning eco-tech innovations is reduced, this will prompt them to increase investment.

\section{Conclusion}

Based on the possible outcomes of the game modeling of the introduction or refusal of the introduction of eco-technological innovations by the companies of the «two maximums», the authors have developed a new pyramid of the energy chain of energy production and storage (Figure 1). The main part of the pyramid is the power grid, represented by the UHV transmission and the DC power supply. It forms the transportation network of the power system together with the former transportation network, natural gas pipeline network and oil transportation. At the bottom of the pyramid are «two highs» companies and investors. The focus of technological innovation and investment on both sides will shift to the new energy production and storage chain. This means that the problem of energy storage will be solved within the framework of the new creation and development of the energy industry. 


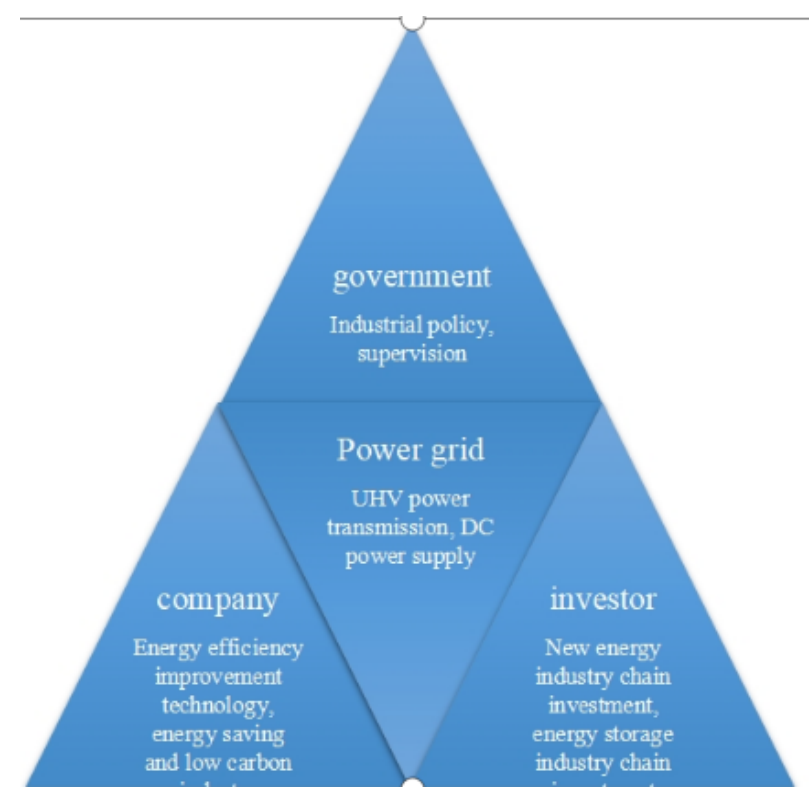

Fig. 1. New pyramid of the chain of energy resources and energy storage.

As shown in Figure 2, new energy sources such as photovoltaic and wind power are in charge of generating electricity, UHV is in charge of power distribution, and new energy vehicles are in charge of consuming reserves, forming a new system for fossil energy diversion and transition to new energy. At the same time, related industries and ancillary facilities in the new energy industry chain and energy storage chain have huge investment potential. 


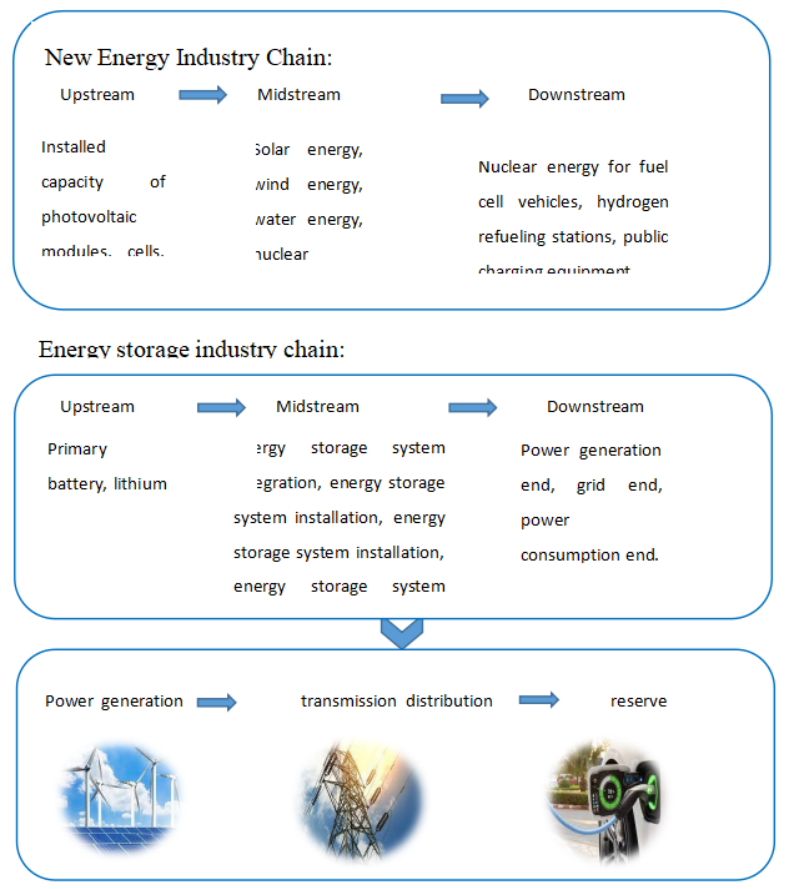

Fig. 2. New energy and new system.

Therefore, in terms of ecology and environmental protection, the new energy system can reduce carbon dioxide emissions and promote the development of low-carbon industries. The economic effect of new eco-technologies consists in the creation of innovations that work on the ecological principles of organizing modern industries in all sectors in order to ensure the transition to a low-carbon model of global development.

The entry of China and other countries into the implementation of the new economic strategy, the use of the new energy system will help stabilize the world order. The technological revolution can lead to the modernization of the industries of the «two maximums», contribute to the reform, and increase in the technological level of production in all countries of the world, which opens a new era of resource use.

\section{References}

1. L. Albrechts, A. Barbanente, V. Monno, Practicing transformative planning: the territory-landscape plan as a catalyst for change, City Territ Archit 7, 1 (2020). Access mode: https://doi.org/10.1186/s40410-019-0111-2

2. S. E. Bibri, J. A. Krogstie, Scholarly backcasting approach to a novel model for smart sustainable cities of the future: strategic problem orientation, City Territ Archit, 6, 3 (2019). Access mode: https://doi.org/10.1186/s40410-019-0102-3

3. D. F. Drake, S. Spinler, Sustainable operations manage-mentan enduring stream or a passing fancy, Manu-facturing and Service Operations Managemen, 15 (4), 13-49 (2013) 
4. J. Xiangtong, The issue of ecological sustainable development from the perspective of scientific and technological innovation, People's Forum·Academic Frontiers, 2, 50-57 (2020)

5. G. Lang, Urban energy futures: a comparative analysis, European Journal of Futures Research, 6, 19 (2018). Access mode: https://doi.org/10.1186/s40309-018-0146-8

6. L. Zirui, S. Zhenqing, C. Linlin, The evolutionary game of green innovation investment of upstream and downstream enterprises under the background of low carbon, Science and Technology Management Research, 39(16), 257-263 (2019)

7. A. Ragheb, R. El-Ashmawy, Strategic actions of urban development to define the intervention policies of slums, City Territ Archit (8), 10 (2021). Access mode: https://doi.org/10.1186/s40410-021-00139-w

8. C. Samaras, J. Apt, I. L. Azevedo, Cap and trade is notenough improving US climate policy, Garnegie Mellon Engineering Carnegie Institute of Technology (2009)

9. T. Qingquan, L. Danglun, Empirical Research on the Motivation and Effects of Government Subsidies: Empirical Evidence from Chinese Listed Companies, Financial Research, 6 (2007)

10. W. Wei, Research on the Carbon Information Disclosure System of Listed Companies Based on the Game Theory Perspective, Accounting Communications, 14, 105-140 (2021) 